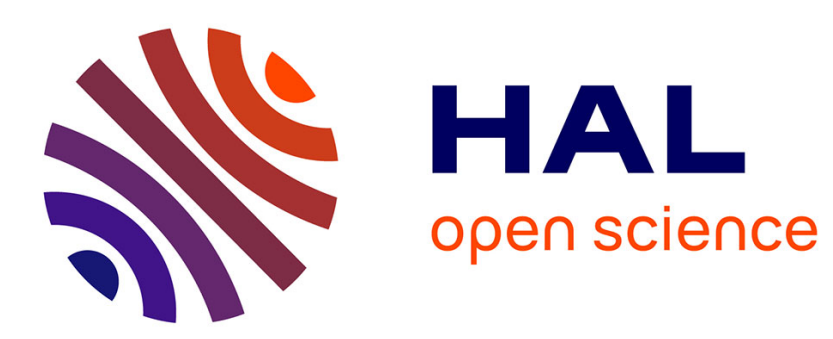

\title{
Microstructure and mechanical properties of some metal matrix composites coatings by laser cladding
}

\author{
Jean Pelletier, P. Sallamand, B. Criqui
}

\section{To cite this version:}

Jean Pelletier, P. Sallamand, B. Criqui. Microstructure and mechanical properties of some metal matrix composites coatings by laser cladding. Journal de Physique IV Proceedings, 1994, 04 (C4), pp.C4-93-C4-96. 10.1051/jp4:1994419 . jpa-00252650

\section{HAL Id: jpa-00252650 https://hal.science/jpa-00252650}

Submitted on 1 Jan 1994

HAL is a multi-disciplinary open access archive for the deposit and dissemination of scientific research documents, whether they are published or not. The documents may come from teaching and research institutions in France or abroad, or from public or private research centers.
L'archive ouverte pluridisciplinaire HAL, est destinée au dépôt et à la diffusion de documents scientifiques de niveau recherche, publiés ou non, émanant des établissements d'enseignement et de recherche français ou étrangers, des laboratoires publics ou privés. 


\title{
Microstructure and mechanical properties of some metal matrix composites coatings by laser cladding
}

\author{
J.M. PELLETIER, P. SALLAMAND and B. CRIQUI* \\ GEMPPM-CALFETMAT, Bât. 403, INSA, 69621 Villeurbanne cedex, France \\ * Renault-Recherche, 9-11 Av. du 18 Juin 1940, 92500 Rueil-Malmaison, France
}

\begin{abstract}
:
During the last decade, many studies have been devoted to metal matrix composites (MMC), consisting of hard ceramic materials embedded in a metallic substrate. The metallic matrix provides the necessary ductility, whilst the hard phase provides the high hardness, the high Young modulus and the good wear resistance.

Laser cladding can be used to elaborate such $M M C$; by adjusting laser power and interaction time, it is possible to melt the metallic elements without affecting the hard phases (oxides, carbides.).

The present work deals with the elaboration and the characterization of MMC coatings on different substrates (copper-or iron-base materials). Metallic matrix is constitued by a nickel base material and tungsten carbides are used as hard particles.
\end{abstract}

\section{I - Introduction :}

Metal matrix composites (MMC) have received considerable interest in the past years (1). MMC combines the toughness with the strength and stiffness of a reinforcing second phase. The reinforcement can be in the form of single crystals platelets or whiskers, short or long fibres, more or less equiaxed particles. This last geometry is of high interest, due to a higher isotropy. Thus, in the present work, particulates reinforcements will be preferred.

Tungsten carbides are used, due to their high melting point (much more elevated than that of the matrix), their good chemical stability and their attractive mechanical properties. In the present work, the possibilities of spray casting by using high power laser $(2,3)$, will be considered, in order to achieve MMC at the surface of different alloys : Fe- or Cu-base alloys. Purpose is to produce a sample with a gradient of properties : the thickness of the MMC surface layer required for most of the technical applications is typically $0.5-1 \mathrm{~mm}$.

\section{II-Experimental procedure:}

Nickel-base alloys combine good corrosion resistance and ductility; their melting temperature is not too elevated, especially in multicomponent alloys, containing $\mathrm{Cr}, \mathrm{B}, \mathrm{Si}, \ldots$. They are often used as intermediate binding layer before plasma spraying of ceramics (especially $\mathrm{ZrO}_{2}$ ). Therefore, nickel-base alloys (granulometry : 45-100 $\mu \mathrm{m}$ ) are presently chosen for the manufacturing of the matrix of the MMC sprayed on $\mathrm{Cu}$ - and Fe-base alloys. particles.

Tungsten carbides (granulometry : 45-100 $\mu \mathrm{m}$ ) are used as reinforcing

Substrates $\left(100^{*} 50^{*} 10 \mathrm{~mm}\right)$ were sand blasted before treatment to improve bonding between deposit and substrate. Compositions are as follows : $\mathrm{Cu}-37 \% \mathrm{Zn}-$ 
$2 \% \mathrm{~Pb}$ (brass), Cu-8\%Sn (bronze), Fe-0.42\%C-1\%Cr-Mo (steel), Fe-3.2\%C-Si (cast iron).

The following system was used for laser cladding :

- a CW CO 2 laser, supplied by CILAS (CI4000),

- a 10" ZnSe focusing lens; the focal point is located in the sample and the laser beam diameter on the specimen surface is about $4 \mathrm{~mm}$. Width of the treated zone is about $1 \mathrm{~mm}$. Parallel tracks are achieved with a shift $\delta=2 \mathrm{~mm}$ between two adjacent treatments.

- a powder injection system (Plasma Technik, Twin 10C); the different powders have been injected, through a coaxial nozzle (4), with argon gas acting as support.

Specimens are mounted on a numerically controlled $X-Y$ table.

For optical microscopy different etching mixtures are used: nital and Klemm III (color reagent) for Fe and Cu-base materials, respectively.

Scanning electron microscopy is performed, on polished and unetched cross-sections. Either backscattered or secondary electrons are used for imaging (BEI or SEI mode). EDS microanalysis was also performed.

$X$-ray diffraction experiments were carried out, with a $\mathrm{Cu} \mathrm{K} \alpha$ radiation.

\section{III-Experimental results and discusssion:}

\section{1-General features of the MMC coatings:}

A selection of suitable processing conditions is required to obtain good MMC, i.e. sound layers (without pores and cracks), homogeneous layers (uniform distribution of carbides particles), good bonding between MMC and susbstrate, without dilution of the addition element (the optimum dilution is about $5 \%$ ).

After optimization, typical values are as follows : laser power $\mathrm{P}=2400$ $3300 \mathrm{~W}$, scanning speed $\mathrm{v}=10-20 \mathrm{~mm} / \mathrm{s}$, defocusing distance $d=40 \mathrm{~mm}$, powder feed rate $F=8-16 \mathrm{~g} / \mathrm{mn}$.

Parameters depend only slightly on the composition of the substrate : suitable parameters for cladding on a steel are also suitable for manufacturing a MMC on a brass or on a bronze.

An example of MMC is shown in fig. 1. The reinforcing particles are distributed uniformly in a dense nickel-base matrix (fig. 2). Thickness of the surface layer is up to $1 \mathrm{~mm}$ in a single track; in order to achieve large areas, parallel tracks are performed, with a shift $\delta$ between two adjacent treatments $(\delta \approx$ $50 \%$ ).

Interface between MMC and substrate is not a straight line, indicating therefore a partial melting of the substrate and hence the formation of a metallurgical bonding between the two parts. This strong bonding is confirmed by four point bending tests, since it is clearly observed that cracking is not followed by a scaling phenomenon, but by a continuous propagation from the coating to the bulk of the specimen.

The X-ray diffraction pattern of the initial powder and of a cladding, evidenced that phases present in the powders are still found in the MMC : reinforcing particles are unaffected during the laser processing.

Temperature during manufacturing of $\mathrm{MMC}$ is an important parameter(5, 6). To measure this value, an optical bicolor pyrometer was used, pointing on the laser-material interaction zone. Experimental curves depend on processing 
parameters (F, P, ...), but not (or only litle), for a given powder, on the composition of the workpiece (steel, brass, ...). Values are in the range 1800$2000^{\circ} \mathrm{C}$, i.e. above melting temperature of metallic elements $(\mathrm{Ni}, \ldots)$, but below that of carbides $\left(W C, W_{2} C, \ldots\right.$ ), which are typically higher than $2500^{\circ} \mathrm{C}$. Therefore heating enables melting of elements which will constitute the matrix, without affecting reinforcing particles.

This temperature registration is in complete agreement with the other results, X-ray diffraction patterns or micrographic observations.

\section{2-Mechanical properties:}

Due to the heterogeneous microstructure of the $\mathrm{MMC}$, either average values or local values are determined. In a nickel-base MMC elaborated on a steel workpiece, matrix hardness is in the range $500-600 \mathrm{HV}$, while carbide hardness is higher than $2500 \mathrm{HV}$. Similar results are observed in the different MMC coatings, elaborated on the various substrates. It may be expected that the existence of these reinforcing particles will have a beneficial effect on tribological properties (especially wear resistance). Fretting tests are now in progress to check this assumption.

\section{IV-Conclusion :}

In this study, it has been shown that high power lasers can be used to manufacture metal matrix composites on many materials ( $\mathrm{Cu}$ - or Fe-base alloys), with a thickness up to $1 \mathrm{~mm}$.

Both metallic and carbide powders are fed continuously into the laser beam where they are heated (metallic elements are melted) and propelled at high velocity onto a prepared workpiece. After solidification, metallic elements constitute the matrix of the MMC, while carbide particles act as reinforcing component.

Reinforcing particles are unaffected by the spraying operation and randomly distributed in the MMC. Sound layers are achieved, without cracks.

MMC features are nearly independent on the composition of the substrate and suitable experimental processing conditions are also very similar.

Four bending points tests evidence the strong bending between the MMC and its support, since no scaling phenomenon is observed during the test.

Mechanical properties (hardness) are good, confirming therefore that laser cladding is a promising primary manufacturing route for the fabrication of various MMCs, which could act as wear resistant layers.

\section{References:}

1 - Clyne, T.W. and Withers, P.J., "An introduction to metal matrix composites", cambridge University Press, Cambridge, UK (1993).

2 - Tucker, T.R., Clauer, A.H., Wright, I.G. and Stopski, J.J., Thin Solid Films, 118 (1984), 73.

3 - Singh, J. and Mazumder, J., Metall. Trans. A, 18, (1987), 313.

4 - Dezert, D., Kinkelin, K., Pelletier, J.M. and Vannes, A.B., Bul. Club Laser Puis., 12 (1992), 48 .

5 - Grunenwald, B. , Shen, J., Dausinger, F. and Hugel, H., Proc. 26thISATA, Aachen, 13-17 Sept. 1993, p. 287.

6 - Sallamand, P. and Pelletier J.M., Mat. Sci. Eng., A171, (1993), 263. 


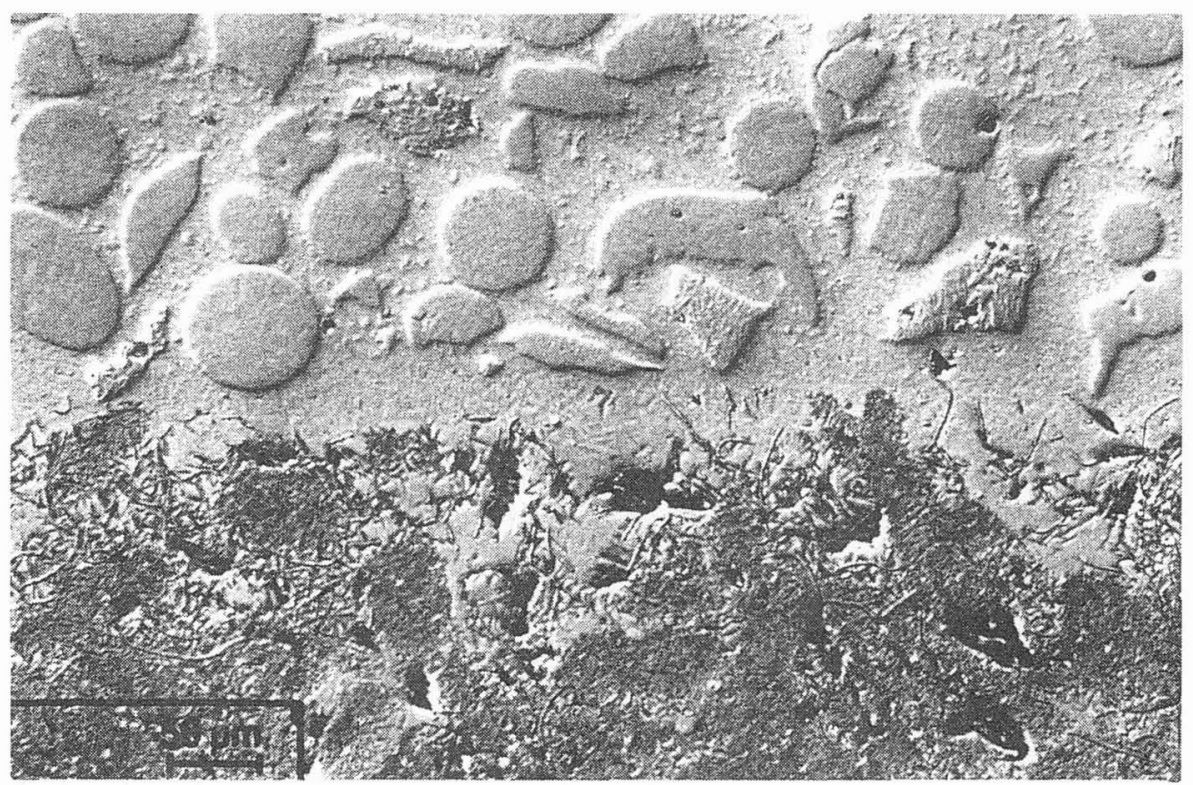

Fig. 1 : MMC produced on a cast iron; reinforcing particles : tungsten carbides.

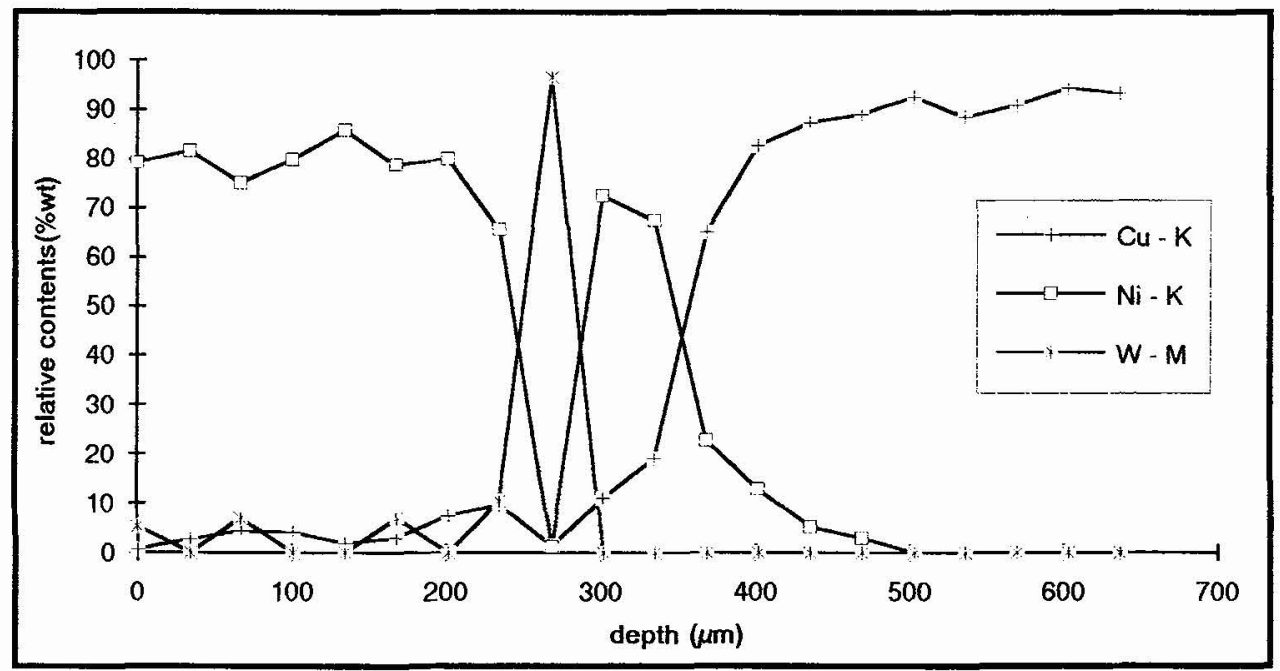

Fig. 2 : concentration profile, determined by EDS, from the top to the bulk of the specimen, in a bronze coated with a MMC. 